FILOLOGÍA HISPÁNICA 



\title{
EL LAZARILLO RELEÍDO EN LA EDICIÓN DE ALCALÁ (1554): SUGERENCIAS NARRATIVAS DESDE LAS «PROFECÍAS» DEL CIEGO
}

\author{
José Antonio Calzón García \\ Universidad de Vilnius (Lituania) \\ joseantoniocalzon@gmail.com
}

\section{RESUMEN}

El artículo, retomando el papel protagónico del eje emisor-receptor en el Lazarillo, analiza las posibilidades narrativas e interpretativas que sugieren las interpolaciones existentes en la primera edición de Alcalá, a partir sobre todo del interrogante que se abre con la interpolación del ciego, en la cual una de sus profecías, a diferencia de todas las demás, parece no verse cumplida.

PalABRAs Clave: Lazarillo, interpolaciones, Alcalá, ciego, profecías.

\section{ABSTRACT}

The article, by taking up the key rol of the speaker-receiver axis in Lazarillo, analyses the narrative and interpretative possibilities suggested by the existing interpolations in Alcalá's first edition, particularly from the question raised by the blind man's interpolation, in which one of his predictions, unlike all other ones, seems not to be realized.

KEYWORDS: Lazarillo, interpolations, Alcalá, blind man, predictions.

La novela seminal del género picaresco, como tantos otros textos de nuestra literatura, se ha prestado, a lo largo de los siglos, a toda clase de interpretaciones, que han hecho de sus páginas una suerte de caleidoscopio ante el cual la conjunción de formas y colores quedaba a 
criterio del exegeta. Así, desde la consideración del texto en cuanto bildungsroman, en el cual Lázaro, en palabras de REY HAZAS (2013: 14), vive un proceso de aprendizaje en el que «abandona su inocencia inicial, comprende que hay que ser avispado para sobrevivir, se hace cargo de que en la sociedad de su tiempo conviene guardar las apariencias y asimila que la nobleza (...) depende de (...) la capacidad para fingirse rico», hasta quienes consideran que la obra «posee las características del género de aventuras» (WITDOUCK, 2014: 13), la novelita se ha prestado a toda suerte de análisis, en función de los intereses históricos, sociológicos, religiosos, narratológicos o lúdicos del lector. Desde cualquiera de los prismas, la crítica contemporánea, en mayor o menor medida, ha articulado el análisis, desde el punto de vista estructural, a partir del valor nuclear que con frecuencia se otorga al caso más célebre de la literatura española:

Lázaro de Tormes, pregonero de Toledo, recoge y aplica en el caso todas las enseñanzas recibidas en su aprendizaje de hombre hecho y derecho; y el espacio de la novela queda definitivamente cerrado y unificado (...) Lázaro escribe para explicar el caso; el caso explica qué y cómo escribe Lázaro (...) La novela se presentaba, así, sometida a un punto de vista: el del Lázaro adulto que protagoniza el caso (RICO, 1982: 35-36).

En efecto, el propio RICO (1988: 171) insistirá en señalar que «el núcleo de toda la narración» es ese caso que «garantiza a un tiempo la verdad y falsedad de la carta del pregonero». El caso, por tanto, articularía un relato construido desde la estructura epistolar a partir de la carta respuesta que el Lázaro-narrador remitiría a un enigmático «Vuestra Merced», fruto de la curiosidad de este ante el misterioso hecho desvelado en el tratado final, que no es otro que el amancebamiento de la mujer del protagonista con el arcipreste de san Salvador.

No descubre nada nuevo NAVARRO DURÁN (2016: 23) cuando afirma que «solo se puede leer con gusto si se entiende (...) lo que se lee (...) si no se acercan los textos literarios a todos los públicos, ese patrimonio literario será (...) un placer reservado a muy pocos (...) El mejor estímulo para la lectura es el fácil acceso al interior». No obstante, frente a la ideal competencia lectora, ante la cual, en palabras de LLUCH (2003: 72), se precisa de conocimientos de índole «genérica, lingüística, intertextual y literaria», lo cierto es que, en el caso particular del Lazarillo, la especial configuración estructural del texto -imbricada de forma indisoluble con la urdimbre narrativo-argumental - hace que la comprensión de la propia historia, y de su desarrollo, solo asome ante los ojos del lector una vez desglosado el papel de cada una de las instancias enunciativas. En este sentido, el triple papel de Lázaro — protagonista, narrador y supuesto autor del texto- ofrece una riqueza semántica sustentada sobre todo en la especial complejidad de su rol en cuanto narrador, en particular en las páginas iniciales y finales de la obrita, momento en el cual el caso — no lo olvidemos, una situación de supuesta infidelidad ante la cual el protagonista aparenta defender, y creerse, la honestidad de todos los agentes implicados en el triángulo amoroso - cobra todo su protagonismo, dejando así la piedra en el tejado del lector: «cuando el lector del Lazarillo descubre que el personaje está engañándose a sí mismo y que pretende transferirle ese engaño, necesariamente procede a una revisión de toda su lectura anterior del texto» (GONZÁLEZ, 1992: 254). En este sentido, no deja de llamar la atención, como igualmente GONZÁLEZ (1992: 254) apuntó, que los destinatarios de la narración — «Vuestra Merced», en calidad de narratario, y un lector implícito más o menos identificado con el lector real- asuman, aparentemente, posturas divergentes en relación al caso a medida que la narración avanza: 
La ambigüedad de Lazarillo deriva (...) de un distanciamiento que se crea, a medida que la narración avanza, entre la visión que el lector implícito tiene de los hechos narrados y la visión del lector explícito (Vuestra Merced) (...) Y tal distanciamiento llega al máximo cuando el lector implícito - lector moderno ya- no puede aceptar las explicaciones finales de Lázaro sobre el «ménage á trois» que, formalmente al menos, deben ser válidas para el destinatario de la «carta».

En efecto, en el Lazarillo nada es lo que parece, y Lázaro juega a ser autor, y narrador, desde la impostura, actitud esta a tener muy en cuenta para una certera interpretación del relato: «el novelista, así, no ofrecía tanto una ficción cuanto una falsificación: un apócrifo, mejor que un anónimo (...) los lectores acometían el libro como pura verdad y acababan encontrando una mentira que instauraba un género de ficción admirablemente nuevo» (RICO, 2006: 32*). Esta impostura o, si se prefiere, este «doble juego» del autor-narrador, surge desde la perspectiva de quien cuenta el despertar a la vida de alguien que, en calidad ya de relator, dista mucho de ser inocente. No en vano, la presencia del Lázaro-personaje, y de sus palabras y pensamientos, van dejando paso poco a poco al discurso predominante del pícaro-narrador, lo que «significa que, a medida que Lázaro-protagonista se aproxima a su Lázaro-narrador, pierde su capacidad crítica» (GONZÁLEZ, 1992: 256) o, si se prefiere, que los discursos de ambos son fundidos, ideológicamente, en el Tratado VII, cuando uno y otro insisten en que «quedamos todos tres bien conformes», con lo cual «hasta el día de hoy nunca nadie nos oyó sobre el caso» (ANÓNIMO, 2006: 134). De este modo, las páginas finales de la obra dejan al lector ante un cuadro de ironía o ambigüedad que permanece fuera del horizone interpretativo de «Vuestra Merced», y que revela, en última instancia, cómo el juego del narrador-autor sobrepasa, con mucho, la simple relación epistolar de una infamia negada.

De cualquiera de las maneras, en el Lazarillo asistimos a la superposición de instancias enunciativas que dotan de más y más complejidad, mediante capas interconectadas, los procesos comunicativos que la obra desgrana. Así, comenzando por el protagonista, siguiendo con el narrador y el autor ficticio de la obra, llegamos al fin al autor real y, sobre todo a propósito del asunto que nos ocupa, al editor-(re)elaborador de una obra de la que conservamos, como es sabido, cuatro primeras ediciones: las de Alcalá, Burgos, Amberes y Medina del Campo — esta última más recientemente encontrada—, todas ellas de 1554.

Largo y tendido se ha hablado de las relaciones genealógicas entre estas primeras ediciones conservadas, y no es el objetivo de estas líneas profundizar en un asunto ya trabajado por los principales eruditos del Lazarillo. Limitémonos a señalar algunos de los principales puntos en lo concerniente al posible estema de la obra. Comenzando por la edición menos estudiada, por su reciente aparición, esto es, la de Medina del Campo, mientras CAÑAS MURILLO (1996) o BLECUA (2003), entre otros, la desvinculan desde el punto de vista editorial de las otras tres, RUFFINATTO (1998: 121) hace derivar a la de Burgos de esta, y CARRASCO (1999) también a la de Amberes. Respecto a las otras tres -Alcalá, Burgos y Amberes-, mientras CASO GONZÁLEZ (1966) considera que la edición de Alcalá provendría de un manuscrito perdido, distinto a otro igualmente extraviado del que proceden las ediciones de Amberes y Burgos — a partir de la suposición de que hacia 1525-1550 habría existido un Libro de Lázaro de Tormes o Lazarillo primitivo, hoy perdido y que habría sido reelaborado en el Lazarillo conocido, el cual constaba de varias partes, tenía forma autobiográfica, narraba sucesos diversos de Lázaro de Tormes y mostraba al protagonista transforma- 
do en otros seres (mujer, pez...) —, RICO (2006: 14*) considera que «los Lazarillos de Alcalá y Amberes proceden de una misma fuente, una edición anterior, hoy perdida, que se remonta a otra que tampoco ha llegado, de la que desciende la impresión de Burgos».

Sea como fuere, de entre las diferencias existentes entre las primeras ediciones que han llegado hasta hoy, llaman especialmente la atención las interpolaciones de la edición de Alcalá, y que, como CAÑAS MURILLO (1996) o FERRER-CHIVITE (2000: 318) han señalado, no figuran en ninguna de las otras tres. A la hora de intentar encontrar una explicación, u origen, para estos añadidos, tres son las opiniones que se han consolidado a lo largo de las décadas (WEINER, 1982): a) quienes, como Martín de Riquer o Adolfo Bonilla y San Martín, consideran que no son del autor original, además de superfluos e impertinentes, y no guardan relación con el texto; b) los que, en la línea de Marcel Bataillon, plantean que tienen cierto interés, sin designarlos como legítimos, y c) aquellos que, en consonancia con críticos y editores como Augusto Escarpizo o Luis Jaime Cisneros, defienden que las interpolaciones son auténticas y legítimas, y que encajan «temática y literariamente» (WEINER, 1982: 827) en la obra en general. Algunos, como CASO (1966: 153), plantearon, en una línea cercana a esta última opinión, que el texto adicional de Alcalá figuraría ya en el primigenio Libro de Lázaro de Tormes, del cual sería tomado, como tantos otros fragmentos — «estas mismas interpolaciones (...) podrían ser (...) fragmentos tomados más o menos directamente del Libro de Lázaro de Tormes (...) en este caso nuestro autor, al reelaborar, seleccionó el material de que disponía»-, si bien otros, como FERRER-CHIVITE (2000: 320), creen que el error de Caso podría radicar en volver complejo en exceso un estema que la lógica tendería a simplificar: «si ese original era el que ya presentaba los fragmentos, evidente es que (Caso) se hubiera ahorrado su hipotético $\mathrm{X}^{\prime}$, siendo que en ese original era donde Al(-calá) —entiéndase Salcedo- hubo de leer los mismos sin necesidad de otros intermediarios». De este modo, FERRER-CHIVITE (2000: 321-323) sostiene, no que Alcalá se base en interpolaciones, sino que Burgos y Amberes - léase en estos casos también Medina del Campo- serían resultado de supresiones llevadas a cabo en un texto anterior común. Así, en una de las interpolaciones más relevantes, presente en el Tratado I, y sobre la cual se volverá con más calma más adelante, Lázaro alude a su llegada a la localidad de Escalona, y a un mesón en particular (ANÓNIMO, 2006: 37 n.): «Yendo que íbamos ansí por debajo de unos soportales, en Escalona, adonde a la sazón estábamos en casa de un zapatero (...) y llegamos a un mesón». Nada tendría de especial si no fuera por el hecho de que Escalona, y el mesón, figuran igualmente en el texto de las cuatro ediciones conservadas, justo a continuación del fragmento interpolado/suprimido: «Estábamos en Escalona, villa del duque della, en un mesón, y diome un pedazo de longaniza que le asase» (ANÓNIMO, 2006: 38). El argumento de FERRER-CHIVITE (2000: 323) surge a partir de la siguiente pregunta: ¿por qué se incluyen Escalona y el mesón en las versiones de Amberes y Burgos, si no había ninguna referencia a ellos en los textos perdidos de los que procederían ambas ediciones? La única explicación, para el crítico, surgiría de la teoría de que Burgos y Amberes - insisto, dejamos fuera Medina del Campo por una simple cuestión de simplicidad - procedan de una versión anterior en la que sí aparecería Escalona, pero, al quitar el fragmento que ha sobrevivido en Alcalá, el editor consideró que había que añadir la referencia espacial — precisamente la misma- en otro sitio, justo a continuación del fragmento interpolado/suprimido, lo que en el caso de Alcalá generó una duplicidad absurda, con la mención de Escalona y del mesón dos veces, con muy pocas líneas de diferencia, fruto de la presencia tanto de la referencia topográfica de Amberes 
y Burgos como del supuesto fragmento suprimido en ambas, donde ya se aludía a dichos lugares, a modo de contextualización: «con lo que, además, hasta se puede concluir que si de alguna real interpolación hay que hablar no es esa que imagina la crítica general sino la de X (fuente de Burgos y Amberes) y su párrafo (la referencia a Escalona)» (FERRER-CHIVITE, 2000: 324). De cualquiera de las maneras, y dada la dificultad para resolver de forma incontestable la polémica en torno a la autoría de los fragmentos interpolados en la edición de Alcalá, quizás quepa, en cuanto salomónica solución intermedia, el juicio de WEINER (1982: 827): «creo que hubiera sido sumamente difícil que éstas (las interpolaciones) fueran hechas por quien no estuviera estrechamente relacionado con la obra, sea como autor, o sea como amigo íntimo del autor».

De entre las interpolaciones de Alcalá, dos destacan de manera especial. Una de ellas, sin peso específico en estas páginas, la encontramos poco antes de concluir el Tratado V (ANÓNIMO, 2006: 123-125 n.), cuando Lázaro aumenta la lista de embustes y engaños del buldero - contando con su propia complicidad y su silencio, puesto que, como apunta CASO GONZÁLEZ (1966: 152), el Tratado V se diferencia de los otros seis del Lazarillo sobre todo por la condición de observador de Lázaro- - a la que habría que añadir, justo a continuación, otra (esta brevísima) interpolación, en el final del capítulo: «aunque me daba bien de comer a costa de los curas y otros clérigos do iba a predicar» (ANÓNIMO, 2006: 125 n.). A este respecto, WEINER (1982: 828) considera que la interpolación del buldero tiene un valor estructural en el relato:

Hace que esta metamorfosis (del protagonista en cuanto cómplice de un engaño) no sea una sorpresa tan brusca e inesperada para el lector sino que desde este momento el lector ya está preparado y acondicionado para ver al protagonista vender su honor y dignidad por algunos bienes materiales.

La segunda interpolación importante, ubicada antes en el texto, en el primero de los tratados, guarda relación, como se ha mencionado, con el viaje del ciego y Lázaro a Escalona. Dada la importancia de este pasaje para el análisis a exponer, optamos por su reproducción íntegra:

A lo cual yo no respondí. Yendo que íbamos ansí por debajo de unos soportales, en Escalona, adonde a la sazón estábamos en casa de un zapatero, había muchas sogas y otras cosas que de esparto se hacen, y parte dellas dieron a mi amo en la cabeza. El cual, alzando la mano, tocó en ellas, y viendo lo que era díjome: - Anda presto, mochacho, salgamos de entre tan mal manjar, que ahoga sin comerlo- - Yo, que bien descuidado iba de aquello, miré lo que era, y como no vi sino cinchas y sogas, que no era cosa de comer, díjele: —Tío, ¿por qué decís eso?—. Respondióme: —Calla, sobrino, según las mañas que llevas, lo sabrás y verás cómo digo verdad-. Y ansí pasamos adelante por el mismo portal, y llegamos a un mesón, a la puerta del cual había muchos cuernos en la pared, donde ataban los recueros sus bestias, y como iba tentando si era allí el mesón adonde él rezaba cada día por la mesonera la oración de la emparedada, asió de un cuerno, y con un gran suspiro dijo: —¡Oh, mala cosa, peor que tienes la hechura! ¡De cuántos eres deseado poner tu nombre sobre cabeza ajena y de cuán pocos tenerte ni aun oír tu nombre por ninguna vía!- C Como le oí lo que decía, dije: —Tío, ¿qué es eso que decís? - - Calla, sobrino, que algún día te dará este que en la mano tengo alguna mala comida y cena —. —No le comeré yo — dije—, y no me la dará—. —Yo te digo verdad; si no, verlo has, si vives-. Y ansí pasamos adelante, hasta la puerta del mesón, adonde pluguiere a Dios nunca allá llegáramos, según lo que me suscedía en él. Era todo lo más que rezaba por mesoneras, y por bodegoneras y turroneras y rameras, y ansí por semejantes mujercillas, que por hambre casi nunca le vi decir oración (ANÓNIMO, 2006: 37 n.). 
Salta a la vista que en la interpolación el papel protagónico lo tiene el ciego, y en particular sus profecías. No parece algo casual, en palabras de WEINER (1982: 833):

Podríamos considerar que o el autor o el enmendador vio después de redactarse el libro que el propósito del papel del ciego no se veía muy claramente (...) parecería que el adicionador consideró que aunque rompiera la ilación en algunos momentos, quería hacer más patente el papel de profeta del amo de Lázaro.

Como apunta igualmente WEINER (1982: 830), el ciego de Lázaro aúna dos tradiciones: la cristiano-medieval, en la cual es un ser negativo que tarde o temprano es burlado por otro, y la clásico-renacentista, en la cual el ciego es objeto de veneración y respeto, por su gran sabiduría, siendo capaz de ver en ocasiones el futuro. En cuanto a la segunda de estas tradiciones, a nadie se le escapa el sentido profético que, en ocasiones, tendrán las palabras del ciego, respecto a la propia vida del protagonista, como bien se encarga aquel de anunciarle: «yo oro ni plata no te lo puedo dar; mas avisos para vivir muchos te mostraré» (ANÓNIMO, 2006: 23). No en vano, todas las profecías del invidente se verán cumplidas de uno u otro modo. En primer lugar, comenzando por el episodio del toro de Salamanca — «Lázaro, llega el oído a este toro y oirás gran ruido dentro dél» (ANÓNIMO, 2006: 23)—, las palabras del ciego encontrarán absoluto cumplimiento tras la calabazada de Lázaro contra la figura de piedra, despertando así de su inocencia. Por otra parte, y en relación con el episodio del nabo y la longaniza, el ciego de nuevo profetizará mientras lavan cara y garganta al muchacho: «-Yo te digo — dijo — que si un hombre en el mundo ha de ser bienaventurado con vino, que serás tú» (ANÓNIMO, 2006: 43). Todo invita a pensar, pues, que el oficio de pregonero de vinos al que el protagonista se dedicará en el último de los tratados no es sino otra concesión a las palabras clarividentes del ciego.

En el caso de la interpolación citada, encontramos igualmente dos profecías. La segunda de ellas — «Calla, sobrino, que algún día te dará este que en la mano tengo alguna mala comida y cena (...) Yo te digo verdad; si no, verlo has, si vives» (ANÓNIMO, 2006: 37 n.) —, mencionada a propósito de un cuerno asido por el ciego, supone sin duda de nuevo un guiño al Tratado VII y al amancebamiento de la mujer de Lázaro con el arcipreste, reforzado por una de las interpolaciones de dicho capítulo:

Aunque en este tiempo siempre he tenido alguna sospechu(e)la y habido algunas malas cenas por esperalla algunas noches hasta las laudes, y aún más, y se me ha venido a la memoria lo que mi amo el ciego me dijo en Escalona, estando asido del cuerno. Aunque, de verdad, siempre pienso que el diablo me lo trae a la memoria por hacerme malcasado, y no le aprovecha (ANÓNIMO, 2006: 132 n.).

Quedaría, pues, por dilucidar el sentido de la primera de las profecías de esta interpolación:

Había muchas sogas y otras cosas que de esparto se hacen, y parte dellas dieron a mi amo en la cabeza. El cual, alzando la mano, tocó en ellas, y viendo lo que era díjome: —Anda presto, mochacho, salgamos de entre tan mal manjar, que ahoga sin comerlo- . Yo, que bien descuidado iba de aquello, miré lo que era, y como no vi sino cinchas y sogas, que no era cosa de comer, díjele: - Tío, ¿por qué decís eso?- Respondióme: —Calla, sobrino, según las mañas que llevas, lo sabrás y verás cómo digo verdad- (ANÓNIMO, 2006: 37 n.). 
La referencia a la soga ha sido interpretada por críticos como FERRER-CHIVITE (2000: 322-323) como alusiva a una de las interpolaciones del Tratado VII, en su edición de Alcalá, al igual que ocurría con la anterior profecía — «profecías que más tarde se harán buenas, y en el mismo orden, en las correspondientes interpolaciones del último»—, y de hecho el propio Lázaro rememorará las palabras de su mentor:

En el cual oficio, un día que ahorcábamos un apañador en Toledo, y llevaba una buena soga de esparto, conoscí y caí en la cuenta de la sentencia que aquel mi ciego amo había dicho en Escalona, y me arrepentí del mal pago que le di, por lo mucho que me enseñó; que, después de Dios, él me dio industria para llegar al estado que ahora estoy (ANÓNIMO, 2006: 129 n.).

Cierto es que el comentario de Lázaro deja bien clara la referencia a las palabras del ciego. De igual modo, y a propósito del episodio del nabo y la longaniza, cabe considerar que el «ahoga sin comerlo» antes citado pudiera aludir también al episodio en el cual Lázaro vomita la longaniza antes de digerirla:

Y con esto, y con el gran miedo que tenía, y con la brevedad del tiempo, la negra longaniza aún no había hecho asiento en el estómago; y lo más principal: con el destiento de la cumplidísima nariz medio cuasi ahogándome, todas estas cosas se juntaron y fueron causa que el hecho y golosina se manifestase y lo suyo fuese vuelto a su dueño (ANÓNIMO, 2006: 40).

Ambas referencias — especialmente la primera - parecen dejar claro que al autor retomó el sentido proyectivo de la profecía de la soga, al aludir de nuevo a ello, páginas más adelante. Sin embargo - y he aquí una cuestión crucial, que diferencia la profecía de la soga de la de los cuernos, el vino o el toro de piedra—, la profecía no se cumple. Es decir, el ciego vaticina que, según el presumible devenir de su vida, Lázaro tarde o temprano comprobará en sus carnes el rigor de la soga, un «manjar» que «ahoga sin comerlo». La pregunta, por tanto, es: ¿yerra el ciego por primera y última vez o realmente hemos de buscar el cumplimiento de su profecía en otro lugar?

Asumamos que, de cumplirse la profecía, Lázaro habría de verse estrangulado - y muerto, en consecuencia - por la acción de una soga de esparto. Sin embargo, como sabemos, la historia no solo concluye con el protagonista indemne —al menos en el plano físico—, sino que la propia verosimilitud del relato autobiográfico obliga a la supervivencia del protagonista-relator. Ahora bien, esto nos lleva a la misma pregunta: ¿es posible contemplar un universo literario en el cual Lázaro hubiera muerto al final del relato?

Recordemos que una de las interpolaciones de la edición de Alcalá consiste en la adición, al final del texto, de la oración «de lo que de aquí adelante me suscediere, avisaré a Vuestra Merced» (ANÓNIMO, 2006: 136 n.), justo a continuación del comentario que cierra todas las demás primeras ediciones: «Pues en este tiempo estaba en mi prosperidad y en la cumbre de toda buena fortuna» (ANÓNIMO, 2006: 135). A propósito del fragmento añadido, FERRER-CHIVITE (2000: 325-326) señala:

Quien no había comprendido la estructura de la obra y, además, había alterado la intención del autor fue precisamente ese manipulador con sus eliminaciones; o quizá fuese mejor decir que sí la había comprendido pero que se decidió por las mismas porque más le convenía para su propósito, para el personal giro que quería dar a la obra, es decir, ese de que ésta fuera una específicamente 
planeada para narrar el «caso» final, que mucho de eso parece desprenderse de la omisión de la frase final de Alcalá, «De lo que de aquí adelante me suscediere avisaré a Vuestra Merced», que, instalando como instala una condición de género abierto, es con la que se abre el portillo para suponer y admitir que bien se han podido dar otro $u$ otros casos que al autor no le importa o no le interesa narrar.

De igual modo, RICO (2006: 136 n.) no solo insiste en el hecho de que la frase final de Alcalá «rompe la estructura cerrada», dejando el final abierto, sino que también señala que el Tratado VII, tal y como lo conocemos, parece, cuando menos, extraño o inconcluso:

Al final del libro no pasa nada (...) Precisemos: no pasa nada superficialmente, no hay una intriga externa capaz de encandilar a quien hubiera empezado la obra por el desenlace. Pero por debajo de esa falta de acción sí pasa — ha pasado — toda la historia de Lázaro (...) No hay acción, entonces, sino contemplación de un personaje, de una actitud. Esa versión de el caso, tan diariamente opuesta a la tradición literaria del ménage à trois, era hacia 1550 una proeza absoluta (RICO, 2006: 126).

La misma idea de que el Lazarillo, y en concreto los dos últimos tratados, parecen más esquemas de capítulos más extensos que textos finalizados y cerrados ha sido defendida también, entre otros, por críticos como Francisco Ayala o Albert A. Sicroff (WEINER, 1982: 829). Por tanto, si hemos de creer tanto a los estudiosos mencionados como a la literalidad de la última oración de Alcalá, dejándonos a la espera de más acontecimientos, algún suceso con relevancia narrativa debería haberle pasado a Lázaro a continuación del punto y final que ha llegado hasta nosotros. Ahora bien, ¿de qué podría tratarse? Pues si hemos de creer en el fiel cumplimiento de todas y cada una de las profecías apuntadas por el ciego, incluidas las interpoladas, solo cabe una posibilidad: Lázaro al final muere ahorcado.

Antes de preguntarnos por la verosimilitud narrativa de dicho desenlace, comencemos haciéndonos dos preguntas: ¿cuál es la conexión entre dicha hipótesis y la edición de Alcalá? y ¿qué lleva a Lázaro a tan violento final? Empezando por la primera, recordemos que la profecía alusiva al «ahoga sin comerlo» de la soga y la invitación a continuar relatando en el futuro a «Vuestra Merced» lo que al protagonista le sucediera figuran solo en las interpolaciones de Alcalá, es decir, las demás ediciones omiten toda referencia a una supuesta muerte no relatada de Lázaro a causa de una soga, al tiempo que dejan el final cerrado, con ese irónico «estaba en mi prosperidad y en la cumbre de toda buena fortuna» (ANÓNIMO, 2006: 135). Por otro lado, y respecto a la segunda de las interrogantes, podemos contemplar dos posibilidades. En primer lugar, y continuando con los lazos, más o menos ocultos, que muestran las distintas interpolaciones, en el episodio del buldero la adición más extensa concluye, tras repasar algunas de las principales tretas del vendedor de bulas, con las siguientes palabras: «me tomó juramento que no descubriese el milagro, y ansí lo hice hasta agora» (ANÓNIMO, 2006: 125 n.). Cabe imaginar, si bien sin indicios para ello — salvo por el quizás ambiguo uso del adverbio «agora», referente al momento de la narración-, que una posterior indiscreción de Lázaro sobre los tejemanejes de su antiguo amo podrían haber llevado a nuestro protagonista a un fatal desenlace, fruto quizás de la venganza. En cualquier caso, y de seguir manteniendo la idea de que Lázaro ve terminar sus días debido a la odiosa acción de una soga, todo nos lleva a pensar, de acuerdo con nuestro conocimiento de la historia, que el quizás inconcluso Tratado VII tenga un papel especial en todo ello, lo que nos lleva a la segunda posibilidad. Así, el evidente amancebamiento de la mujer de Lázaro con el 
arcipreste, contando con el consentimiento del pícaro, era una conducta penada, tal y como menciona RICO (2006: 130 n.), en relación con una pragmática de 1577:

A los maridos que por precio consintieren que sus mujeres sean malas de cuerpo..., les sea puesta la mesma pena que por leyes de nuestros reinos está puesta a los rufianes, que es, por primera vez, vergüenza pública y diez años de galeras, y, por segunda vez, cien azotes y galeras perpetuas.

Nada hay aquí, sin embargo, que invite a pensar en la pena de horca. No obstante, RODRÍGUEZ SÁNCHEZ (1994: 25-26) señala que en los Siglos de Oro la aplicación de la pena de horca cubría un amplio espectro de delitos, no siempre de extrema gravedad:

La soga, la escalera, el envión del verdugo, se reserva para homicidas, asesinos, ladrones, salteadores, amancebados notorios, falsificadores, corruptos, deudores de poca monta, reincidentes de toda clase, presidiarios incorregibles y hombres a quienes la duda de la justicia convierte en personajes inconvenientes de los que es mejor deshacerse.

De igual modo, el propio RODRÍGUEZ SÁNCHEZ (1994: 25 n.) menciona la presencia de la horca en cuanto castigo en relatos picarescos como el Buscón, sin ir más lejos, a propósito del final del progenitor del protagonista. En cualquier caso, bien por sus pecados o secretos del pasado, bien por el ménage à trois al que asistimos en el último de los tratados o simplemente a causa de sucesos aún no narrados, pero factibles en el futuro, nada impide pensar que Lázaro, tarde o temprano, probara los rigores de la soga, quizás dando con sus huesos en el cadalso. Sin embargo, y al margen de la posibilidad de la propuesta, quedaría un problema capital por resolver: de estar Lázaro muerto, ¿quién asume la autoría de la obra, respetando así su verosimilitud?

Recordemos que Rosa Navarro Durán (VALDÉS, 2003: 13-16) considera que dos son los agentes que asumen, en el texto, la elaboración física de la obra: Lázaro, por una parte, dirigiéndose a «Vuestra Merced», y otro, más inespecífico, que no marca de forma explícita al destinatario de su obra, y que apela tan solo al supuesto aprovechamiento del texto por parte de una hipotética colectividad: «desta nonada que en este grosero estilo escribo, no me pesará que hayan parte y se huelguen con ello todos los que en ella algún gusto hallaren, y vean que vive un hombre con tantas fortunas, peligros y adversidades» (ANÓNIMO, 2006: 8-9). La explicación para este supuesto desdoblamiento radicaría en la desaparición de un folio que separaría al prologuista desconocido de la primera de las intervenciones de Lázaro, en calidad de escritor de sus memorias a modo de carta-respuesta a «Vuestra Merced». Al eliminarse esa separación, ambos agentes aparecerían fusionados en uno solo, encarnado por la figura de Lázaro. De aceptar la teoría de Navarro Durán, cabría contemplar la posibilidad de que un Lázaro aún vivo habría escrito esa carta-respuesta a «Vuestra Merced» que constituye el Lazarillo, comenzando por el «Suplico a Vuestra Merced reciba el pobre servicio de mano de quien lo hiciera más rico (...) Y pues Vuestra Merced escribe se le escriba y relate el caso muy por extenso (...) porque se tenga entera noticia de mi persona» (ANÓNIMO, 2006: 10-11). No obstante, algo habría llevado a su fallecimiento, tras la redacción de la carta y de su justificación, y sería entonces el enigmático prologuista de las líneas anteriores quien, renunciando ya al formato autobiográfico, asumiría la responsabilidad última de la elaboración del texto, en calidad de amanuense e introductor del pícaro: «Yo por bien tengo que cosas tan 
señaladas y por ventura nunca oídas ni vistas, vengan a noticia de muchos (...) y se huelguen con ello todos los que en ella algún gusto hallaren, y vean que vive un hombre con tantas fortunas, peligros y adversidades» (ANÓNIMO, 2006: 3 y 9).

En conclusión, entre las interpolaciones de la edición de Alcalá del Lazarillo llama poderosamente la atención el fragmento que incluye dos profecías del ciego, por el hecho de que una de ellas, que vaticina la muerte de Lázaro, «según las mañas que llevas» (ANÓNIMO, 2006: 37 n.), fruto de una soga, no se cumple, a diferencia de todas las demás. Ni siquiera el recuerdo por parte del protagonista de la profecía del ciego, en el último de los tratados, sirve para que esta se vea cumplida: el ciego ha predicho la muerte de Lázaro, pero esta, simple y llanamente, no tiene lugar. Ahora bien, motivos no parecen faltar para su muerte; desde el conocimiento de los tejemanejes del buldero hasta su deshonrosa e incómoda situación, al final de la obra, pasando por todo un historial — respecto al cual ignoramos cuánto sabemos— de engaños y hurtos, pasados y quizás futuros, todo invita a pensar que la justicia — para la que el recurso de la horca en modo alguno suponía la existencia, como hemos mencionado, de delitos de sangre- o un posible enemigo conocido o ignorado por el lector pudiera poner el lazo de esparto alrededor del cuello de Lázaro, dando así fin a los días de nuestro protagonista. De ser así, solo la asunción de que las primeras líneas de la obra no son de su autoría permitiría comprender que la profecía del ciego se ha cumplido sin resquebrajar la verosimilitud de la obra. De este modo, la posible muerte de Lázaro permitiría conectar cinco de las interpolaciones de la edición de Alcalá, al relacionar 1) las profecías del ciego — donde se anuncia su fallecimiento, de forma violenta - con 2) y 3) las referencias a estas en el último de los tratados, al tiempo que 4) el final abierto — «De lo que de aquí adelante me suscediere, avisaré a Vuestra Merced» (ANÓNIMO, 2006: 136 n.) — habilita la puerta de entrada a un desenlace del protagonista aún por venir, quizás de algún modo relacionado con 5) los «secretillos» del buldero conocidos por nuestro pícaro.

Sin duda, la audacia narrativa que supondría considerar que la obra, una carta-relato, es prologada por alguien diferente al autor-protagonista, debido a la muerte de este, tan solo sugerida en la narración, sobrepasa probablemente las posibilidades narrativas que contemplaba un novelista del siglo XVI, por muy autor del Lazarillo que fuera. Ahora bien, la probable existencia de dos voces en el prólogo, sumado a un Tratado VII con bastantes opciones de estar inconcluso o de haber llegado hasta nosotros mutilado, más una profecía necesitada de su cumplimiento, llevan a plantear más de un interrogante acerca de los senderos trazados por la historia narrada en el Lazarillo. Al margen de la polémica sobre la autoría de estas interpolaciones, sean o no responsabilidad del autor del resto del relato, lo cierto es que dejan la puerta abierta para un nuevo universo de posibilidades narrativas e interpretativas que sumar al subtexto de insinuaciones e historias a medio contar, en medio de ese laberinto de lecturas entre líneas que nos ofrece el Lazarillo.

\section{REFERENCIAS BIBLIOGRÁFICAS}

Anónimo (2006): Lazarillo de Tormes, Madrid, Cátedra.

Blecua Perdices, Luis Alberto (2003): «La edición del «Lazarillo» de Medina del Campo (1554) y los problemas metodológicos de su filiación», Salina: revista de lletres, 17, pp. 59-70. 
Cañas Murillo, Jesús (1996): Una nueva edición de «Lazarillo de Tormes»: Medina del Campo, 1554, Hesse, Institut für Romanische Philologie de la Philipps-Universität de Marburg.

CArrasco, FéLIx (1999): «La transmisión textual del Lazarillo a la luz de Medina del Campo (1554)», Edad de Oro, XVIII, pp. 47-70.

Caso González, José (1966): «La génesis del Lazarillo de Tormes», Archivum, XVI, pp. 129-155.

Ferrer-Chivite, Manuel (2000): «Sobre las así llamadas interpolaciones de Alcalá», en Florencio Sevilla y Carlos Alvar (eds.), Actas del XIII Congreso de la Asociación Internacional de Hispanistas, Madrid, Castalia, pp. 318-326 (vol. I).

GonZÁlez, Mario M. (1992): «Novela moderna, narrador y lectores en el Lazarillo de Tormes», Abeh, 2, pp. 253-257.

Lluch, Gemma (2003): Análisis de narrativas infantiles y juveniles, Cuenca, Ediciones de la Universidad de Castilla-La Mancha.

Navarro Durán, Rosa (2016): «Las adaptaciones de los clásicos: puentes hacia islas de tesoros», Edetaria, 49, pp. 17-28.

Rey HaZas, Antonio (2013): «Introducción», en Lazarillo de Tormes, Barcelona, Vicens Vives, pp. 7-26.

Rico, Francisco (1982): La novela picaresca y el punto de vista, Barcelona, Seix Barral.

- (1988): Problemas del «Lazarillo», Madrid, Cátedra.

- (2006): «Introducción», en Lazarillo de Tormes, Madrid, Cátedra.

RodRíguez SÁNCHEZ, Ángel (1994): «La soga y el fuego. La pena de muerte en la España de los siglos XVI y XVII», Cuadernos de Historia Moderna, 15, pp. 13-39.

Ruffinatto, Aldo (1998): «A propósito de El Lazarillo de Tormes: Medina y las nuevas fronteras textuales del Lazarillo», Voz y Letra, IX, 2, pp. 87-121.

VAldÉs, Alfonso DE (2003): La vida de Lazarillo de Tormes, y de sus fortunas y adversidades, Barcelona, Octaedro.

WeINER, JACK (1982): «Las interpolaciones en el Lazarillo de Tormes (Alcalá de Henares, 1554), con énfasis especial sobre las del ciego», en Eugenio de BUSTOS (coord.), Actas del cuarto Congreso Internacional de Hispanistas, Salamanca, Universidad de Salamanca, pp. 827-834 (vol. II).

WitdoucK, Sally (2014): Las adaptaciones infantiles de «Lazarillo de Tormes», Gante, Universidad de Gante. 
